\title{
駆動冗長性をもつ閉リンク機構の動力学解析
}

\author{
吉川恒 夫* 横小路泰義* 渡辺 直 満*

\section{Dynamics Analysis of Closed Link Mechanisms with Redundant Actuators}

\section{Tsuneo YOSHIKAWA Yasuyoshi YOKOKOHJI Naomitsu WATANABE}

Closed link mechanisms are useful for tasks that require high speed, high precision, and large payload capacity. It is expected that this kind of mechanisms will be used widely in future. A closed link mechanism with redundant actuators, which is called redundant actuator system, has the potential to make the maximum payload larger.

This paper discusses computational schemes of the inverse and forward dynamics of closed link mechanisms with redundant actuators, which are applicable to wider cases than former method. Then we give an example of cooperative manipulation by two robot arms, and the inverse dynamics is given using the proposed computational scheme. The proposed method enables us to obtain a general solution of closed link dynamics without calculating internal forces.

Key Words : Closed link mechanism, Redundant actuator, Inverse dynamics

\section{1.は じめに}

閉リンク機構は剛性が高く, しかも可動部を軽量化で きるので，高速・高精度・高負荷の作業に適しており，

幅広い分野での応用が期待されている.

閉リンク機構の動力学は, ラグランジュ関数を求めラ グランジュの方程式により計算が行われることが一般的 であるが，効率的な計算法とは言えない，そこで，ルー プの一端を切り離し，仮想トリー構造の力学系とした 上で, 切り離した端点の変位が等しいという拘束条件 を導入する方法について, 研究が行われている(12)3). Nakamura らは拘束条件を能動関節に関する受動関節 のヤコビ行列として表して開リンク機構の理論に鲎着さ せている233.

一般的な閉リンク機構は閉ループ内に受動関節を数個 もち，能動関節位置により受動関節位置が定まる.ここ で構造的に可制御であるための受動関節の最大数は閉リ ンクの構造に依存し, 平面リンクの一般的な場合で 3 ,

\footnotetext{
原稿受付 1992 年 11 月 4 日
}

* 京都大学工学部
一般の空間リンクでは 6 となる. それがこの最大数より 小さい場合には閉リンク機構は圥長なアクチュエータを もつことになり, 与えられた運動から関節トルクへの変 換は一意には定まらない.このよらな閉リンク機構をて 長駆動系とよぶ. Nakamura らはこの圥長性を利用し て駆動圥長性のある閉リンク機構が, 非圥長駆動系の閉 リンク機構において各アクチュエータの出力を大きくし た場合に比べて最大負荷能力を大きくしたり, 応答速度 を高める可能性をもつことを示している2)3. しかし， 彼らは, 式の導出において受動関節の存在を仮定してお り，すべてが能動関節であるような系は扱えない。ま た, 切断点の任意性にも制約がある.すべてが能動関節 であるような系は, 複腕協調作業などにみられ，さらに 受動関節が存在してもとの摩擦力が無視できないときに は能動関節のみからなる系と同様な扱いが必要となる.

本論文では，このよらな駆動冗長性をもつ閉ループ系 を形成するロボット機構について, Nakamura らの方 法 ${ }^{8)}$ 基礎にして, より適用範囲の広い逆動力学および 順動力学の計算法を提案する. 


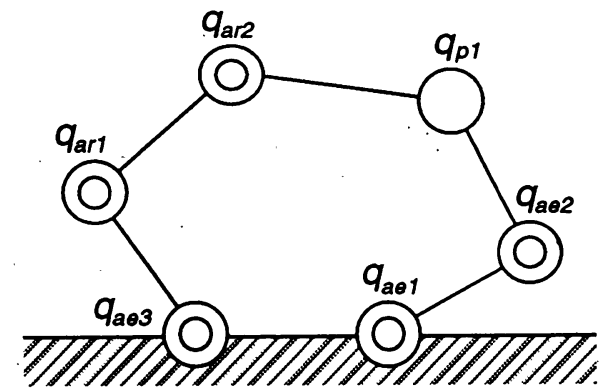

(O) active joint

Fig. 1 Original redundant actuator system

\section{2. 逆動力学}

提案する冗長駆動系閉リンク機構の逆動力学の計算法 を以下に示す.

ステップ 1 Fig. 1 に示すもとのて長駆動系において 適当に選んだて長な能動関節を受動関節と見なした （関節トルクを0とした）非圥長駆動系を考える.

(Fig. 2)（受動関節と見なす圥長な能動関節の選び方 は, 非冗長駆動系にしたとき能動関節の速度により受 動関節の速度が一意に定まるように選ぶ.）

ステップ 2 Nakamura らの手順により非圥長駆動系 の関節トルクを求める.すなわち,

（a） 適当な受動関節で仮想的に切断し仮想トリー構 造をつくる.このとき，切断されなかった受動 関節には仮想的なアクチュェータを仮定する.

(Fig. 3)

(b) 閉リンク機構に要求される運動とまったく同じ 運動をするものとして，仮想トリー構造の関節 トルクを求める.

（c）仮想トリー構造の関節トルクから拘束条件を考 慮することにより，もとの非冗長駆動系の関節 トルクを求める.

ステップ 3 非圥長駆動系の関節トルクから各関節間の 拘束関係を考虑することにより，もとの圥長駆動系閉 リンク機構の関節トルクを求める.

この計算法の新しい点は, ステップ 2 すなわち Nakamura らの方法 ${ }^{3)}$ の前後に新たにステップ 1 と 3 を加え るところにあり, これにより, 閉リンク機構の逆動力学 問題がすべての関節が能動関節である場合や，能動関節 で切断して仮想トリー構造をつくる場合にも解くことが できるようになる。

この計算を定式化すると以下のようになる. まず, す とのて長駆動系の関節 $\boldsymbol{q}$ を以下のように分解する.

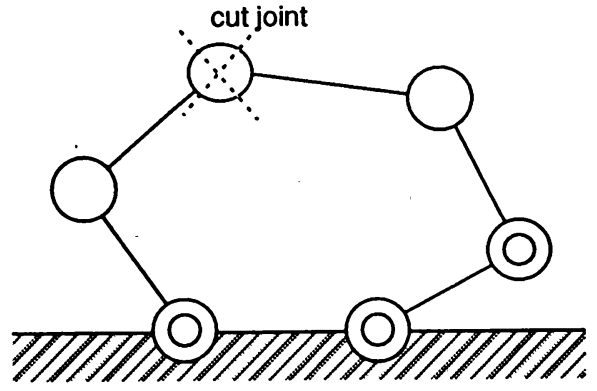

Fig. 2 Non-redundant actuator system

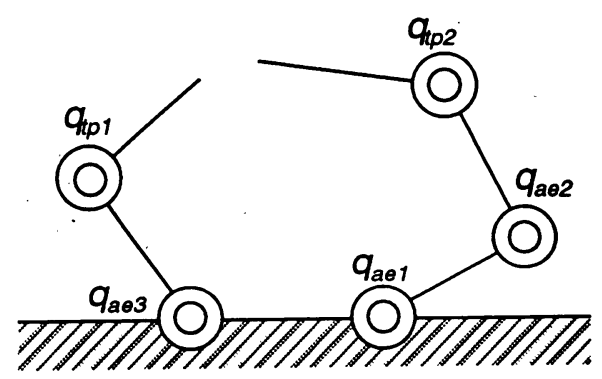

Fig. 3 Virtual tree-structure mechanism

$$
\boldsymbol{q}=\left[\begin{array}{ll}
\boldsymbol{q}_{a}{ }^{T} & \boldsymbol{q}_{p}{ }^{T}
\end{array}\right]^{T}
$$

たたし, $\boldsymbol{q}_{a} \in \boldsymbol{R}^{N_{a}}$ は能動関節, $\boldsymbol{q}_{p} \in \boldsymbol{R}^{N_{p}}$ はは受動関節 に対応する.するとステップ 1 における操作は,

$$
\begin{aligned}
& \boldsymbol{q}_{a}=\left[\begin{array}{ll}
\boldsymbol{q}_{a e^{T}} & \boldsymbol{q}_{a r}{ }^{T}
\end{array}\right]^{T} \\
& \boldsymbol{\tau}_{a}=\left[\begin{array}{ll}
\tau_{a e^{T}} & \boldsymbol{\tau}_{a r}{ }^{T}
\end{array}\right]^{T}
\end{aligned}
$$

と表せる.ただし， $\boldsymbol{q}_{a e}, \boldsymbol{\tau}_{a e} \in \boldsymbol{R}^{N_{a}}$ は非圥長駆動系にし たときの能動関節に, $\boldsymbol{q}_{a r}, \boldsymbol{\tau}_{a r} \in \boldsymbol{R}^{N_{a r}}$ は冖長な能動関節 に対応し， $N_{a}=N_{a e}+N_{a r}$ である. $\boldsymbol{q}_{a r}$ は $\boldsymbol{q}_{a e}$ の位置 により拘束をうけて，一般的に次の関係をもつ。

$$
\boldsymbol{F}_{r}\left(\boldsymbol{q}_{a r}, \boldsymbol{q}_{a e}\right)=\mathbf{0}
$$

ただし $\boldsymbol{F}_{r}$ は $N_{a r}$ 次元ベクトル値関数である. このと き圥長な能動関節の微小変位について次式が成り立つ.

$$
\frac{\partial \boldsymbol{F}_{r}}{\partial \boldsymbol{q}_{a r}{ }^{T}} \delta \boldsymbol{q}_{a r}+\frac{\partial \boldsymbol{F}_{r}}{\partial \boldsymbol{q}_{a e}{ }^{T}} \delta \boldsymbol{q}_{a e}=\mathbf{0}
$$

上式で, $\frac{\partial \boldsymbol{F}_{r}}{\partial \boldsymbol{q}_{a r}{ }^{T}} \in \boldsymbol{R}^{N_{a r} \times N_{a r}}$ が正則でないときは, $\boldsymbol{q}_{a e}$ の 位置により $\boldsymbol{q}_{a r}$ の位置が定まらず，非圥長駆動系の関 節トルクを求めることができない，そこで，ここでは $\frac{\partial \boldsymbol{F}_{r}}{\partial \boldsymbol{q}_{a r}{ }^{T}}$ の正則性を仮定する.

つぎにステップ 2 の（a）において仮想トリー構造の 関節角 $\boldsymbol{q}_{t}$ と関節トルク $\boldsymbol{\tau}_{t}$ を以下のように表す.

$$
\begin{aligned}
& \boldsymbol{q}_{t}=\left[\begin{array}{lll}
\boldsymbol{q}_{a e} e^{T} & \boldsymbol{q}_{t p^{T}}
\end{array}\right]^{T} \\
& \boldsymbol{\tau}_{t}=\left[\begin{array}{ll}
\boldsymbol{\tau}_{a e^{T}} & \boldsymbol{\tau}_{t p}{ }^{T}
\end{array}\right]^{T}
\end{aligned}
$$

ただし， $\boldsymbol{q}_{t p}, \boldsymbol{\tau}_{t p} \in \boldsymbol{R}^{N_{t p}}$ は $\boldsymbol{q}_{p}$ と $\boldsymbol{q}_{a r}$ から切断関節を 除いた関節に対応する.（b）においては開ループリン グ機構に対する関節トルクをニュートン・オイラー法や 
ラグランジュ法などの方法によって $\tau_{t}$ が計算される. ついで (c) では, 非圥長駆動系の関節トルク $\tau_{a e}$ が以 下の式で計算される3).

$$
\boldsymbol{\tau}_{a e}=\boldsymbol{W}_{p} \boldsymbol{\tau}_{t}
$$

ただし $\boldsymbol{W}_{p}=\left[\begin{array}{ll}\boldsymbol{E} & \boldsymbol{J}_{p}{ }^{T}\end{array}\right]^{T}, \quad \boldsymbol{J}_{p}=\frac{\partial \boldsymbol{q}_{t p}}{\partial \boldsymbol{q}_{a e^{T}}}$ である。

最後にステップ 3 で用いる計算法を述べる.（8）式 より

$$
\delta \boldsymbol{q}_{a r}=-\left(\frac{\partial \boldsymbol{F}_{r}}{\partial \boldsymbol{q}_{a r}{ }^{T}}\right)^{-1}\left(\frac{\partial \boldsymbol{F}_{r}}{\partial \boldsymbol{q}_{a e}{ }^{T}}\right) \delta \boldsymbol{q}_{a e}=\frac{\partial \boldsymbol{q}_{a r}}{\partial \boldsymbol{q}_{a e}{ }^{T}} \delta \boldsymbol{q}_{a e}
$$

であるから午長駆動系の微小变位は

$$
\begin{aligned}
\delta \boldsymbol{q}_{a} & =\boldsymbol{W}_{r} \delta \boldsymbol{q}_{a e} \\
\boldsymbol{W}_{\boldsymbol{r}} & =\left[\begin{array}{ll}
\boldsymbol{E} & \boldsymbol{J}_{\boldsymbol{r}}{ }^{T}
\end{array}\right]^{T}
\end{aligned}
$$

で表される. $\boldsymbol{E} \in \boldsymbol{R}^{N_{a e} \times N_{a e}}$ は単位行列, $\boldsymbol{J}_{r}=\frac{\partial \boldsymbol{q}_{a r}}{\delta \boldsymbol{q}_{a e}{ }^{T}}$ は 能動関節に関する冗長な能動関節のヤコビ行列である. 与えられた運動に必要な冗長駆動系の関節トルク $\boldsymbol{\tau}_{a}$ は 同じ運動を行ら非圥長駆動系の関節トルク $\boldsymbol{\tau}_{a e}$ から以下 のよらに計算される（証明は付録参照）.

$$
\boldsymbol{W}_{r} \boldsymbol{T}_{a}=\boldsymbol{\tau}_{a e}
$$

(11) 式より

$$
\boldsymbol{\tau}_{a}=\boldsymbol{W}_{\boldsymbol{r}}^{T^{+}} \boldsymbol{\tau}_{a e}+\left(\boldsymbol{E}-\boldsymbol{W}_{\boldsymbol{r}} \boldsymbol{W}_{r}^{+}\right) \boldsymbol{k}
$$

$\boldsymbol{k} \in \boldsymbol{R}^{N_{a b}+N_{a r}}$ は圥長性を表すパラメータであり，

$$
W_{r}^{T+}=W_{r}\left(W_{r}^{T} W_{r}\right)^{-1}
$$

は $\boldsymbol{W}_{r}^{T}$ の疑似逆行列である. $\boldsymbol{W}_{r}$ のランクは $N_{a e}$ であ るから $\boldsymbol{k}$ の係数行列 $\boldsymbol{E}-\boldsymbol{W}_{r} \boldsymbol{W}_{r}^{+}$のランクは $N_{a r}$ で ある. いま $\boldsymbol{V} \in \boldsymbol{R}^{\left(N_{a \varepsilon}+N_{a r}\right) \times N_{a r}}$ を $\boldsymbol{W}_{r}^{T}$ の零空間の線形 独立なベクトルから作られた行列とすると，(12）式は

$$
\boldsymbol{\tau}_{a}=\boldsymbol{W}_{r}{ }^{T+} \boldsymbol{\tau}_{a e}+\boldsymbol{V} \boldsymbol{\alpha}
$$

となる.ただし $\boldsymbol{\alpha} \in \boldsymbol{R}^{N_{a r}}$ は午長性を表す任意のパラメ 一タである. したがって，3段階目の計算には（14）式 を用いればよいことになる。

\section{3. 順動力学}

仮想トリー構造の運動方程式を一般的に次式のように 書く.

$$
\boldsymbol{M}_{t} \ddot{\boldsymbol{q}}_{t}+\boldsymbol{h}_{t}=\boldsymbol{\tau}_{t}
$$

ただし， $\boldsymbol{M}_{t} \in \boldsymbol{R}^{\left(N_{a \theta}+N_{p}\right) \times\left(N_{a \theta}+N_{p}\right)}$ は慣性行列, $\boldsymbol{h}_{t} \in$ $\boldsymbol{R}^{N_{a} \circ+N_{p}}$ は遠心力, コリオリ力, 拉よび重力負荷を表す 項である.

いま，圥長駆動系に関節トルク $\boldsymbol{\tau}_{a}$ を加えたときの運 動は, 同じ運動をおこなら非圥長駆動系の関節トルク $\boldsymbol{\tau}_{a e}$ と (11) 式で結ばれ，この非圥長駆動系の関節トル ク $\tau_{a e}$ は, 同じ運動をおこなら仮想トリー構造の関節卜 ルク $\tau_{t}$ と（8）式で結ばれる.これらの式に（15）式 を代入して次式を得る.

$$
\boldsymbol{W}_{p}{ }^{T}\left(\boldsymbol{M}_{t} \ddot{\boldsymbol{q}}_{t}+\boldsymbol{h}_{t}\right)=\boldsymbol{W}_{\boldsymbol{r}} \boldsymbol{\tau}_{a}
$$

いま，次式が成り立つ.

$$
\dot{\boldsymbol{q}}_{t}=\dot{\boldsymbol{W}}_{p} \dot{\boldsymbol{q}}_{a e}
$$

この式をもら一度時間微分して, 次式を得る.

$$
\ddot{\boldsymbol{q}}_{t}=\boldsymbol{W}_{p} \ddot{\boldsymbol{q}}_{a e}+\boldsymbol{W}_{p} \dot{\boldsymbol{q}}_{a e}
$$

これを（16）式に代入すると，

$$
\boldsymbol{W}_{p}{ }^{T}\left(\boldsymbol{M}_{t} \boldsymbol{W}_{p} \ddot{\boldsymbol{q}}_{a e}+\boldsymbol{M}_{t} \dot{\boldsymbol{W}}_{p} \boldsymbol{q}_{a e}+\boldsymbol{h}_{t}\right)=\boldsymbol{W}_{r}^{T} \boldsymbol{\tau}_{a}
$$

となる. $\boldsymbol{W}_{p}^{T} \boldsymbol{M}_{t} \boldsymbol{W}_{p} \in \boldsymbol{R}^{N_{a b} \times N_{a e}}$ が閉リンク機構の慣性 行列で, これを $\boldsymbol{M}_{c}$ とし, この逆行列を両辺にかけて, 次の順動力学の方程式を得る.

$$
\ddot{\boldsymbol{q}}_{a e}=\boldsymbol{M}_{c}^{-1}\left(\boldsymbol{W}_{r}^{T} \boldsymbol{\tau}_{a}-\boldsymbol{W}_{p}{ }^{T} \boldsymbol{M}_{t} \dot{\boldsymbol{W}}_{p} \dot{\boldsymbol{q}}_{a e}-\boldsymbol{W}_{p} \boldsymbol{T}_{t}\right)
$$

さらに（9）式より,

$$
\ddot{\boldsymbol{q}}_{a r}=\boldsymbol{J}_{r} \ddot{\boldsymbol{q}}_{a e}+\dot{\boldsymbol{J}}_{r} \dot{\boldsymbol{q}}_{a e}
$$

を得る。

\section{4. 数 値 例}

駆動冗長性を有する閉リンク機構の 1 つに 2 本のロボ ットアームによる協調作業が挙げられる. 各アームのモ デルは Fig. 4 のように平面 3 自由度とした. 各アーム は対象物を強固に把持しているものとすると，この系は 能動関節のみからなるて長駆動系閉リンク機構とみなす ことができ前に述べた逆動力学計算法を用いて与えられ た目標軌道に対する関節トルクを求めることができる.

罒に示すように第 1 アームの関節 $i$ の関節角を $\alpha i$, 第 2 アームの関節 $i$ の関節角を $\beta_{\imath}$ とし，また Fig. 5 のように, リンク $i$ の長さを $l_{i}$ 各アームの関節 1 間の 距離を $l_{0}$ とし, このリンクの動力学パラメータを Table 1 のように与えた. このとき，第2アームの関節 3 で切断し，仮想トリー構造として逆動力学計算をおこ なう手順を以下に述べる.

$$
q=\left[\alpha_{1}, \alpha_{2}, \alpha_{3}, \beta_{1}, \beta_{2}, \beta_{3}\right]^{T}
$$

の中か $\boldsymbol{q}_{a e}$ を以下のように選ぶ

$$
\boldsymbol{q}_{a e}=\left[\alpha_{1}, \alpha_{2}, \alpha_{3}\right]^{T}
$$

関節間関係式 (4) は以下のようになる.

$$
\begin{gathered}
\alpha_{1}+\alpha_{2}+\alpha_{3}+\beta_{1}+\beta_{2}+\beta_{3}=2 \pi \\
l_{0}+l_{1} C_{\alpha 1}+l_{2} C_{\alpha 12}+l_{3} C_{\alpha 123}+l_{1} C_{\beta_{1}}+l_{2} C_{\beta_{12}}=0 \\
l_{1} S_{\alpha 1}+l_{2} S_{\alpha 12}+l_{3} S_{\alpha 123}-l_{1} S_{\beta_{1}}-l_{2} S_{\beta_{12}}=0
\end{gathered}
$$

Table 1 Parameters of numerical example

\begin{tabular}{|c|c|c|c|c|}
\hline Link & $\begin{array}{c}\text { Length } \\
{[\mathrm{m}]}\end{array}$ & $\begin{array}{c}\text { Length to center } \\
\text { of gravity }[\mathrm{m}]\end{array}$ & $\begin{array}{c}\text { Mass } \\
{[\mathrm{kg}]}\end{array}$ & $\begin{array}{c}\text { Inertia of } \\
\text { moment }\left[\mathrm{kg} \mathrm{m}^{2}\right]\end{array}$ \\
\hline \hline 1 & 0.25 & 0.18 & 20.0 & 0.45 \\
\hline 2 & 0.30 & 0.15 & 30.0 & 0.80 \\
\hline 3 & 0.30 & 0.15 & 15.0 & 0.30 \\
\hline \multicolumn{2}{|c|}{ Length between two arms [m] } & 0.40 \\
\hline
\end{tabular}




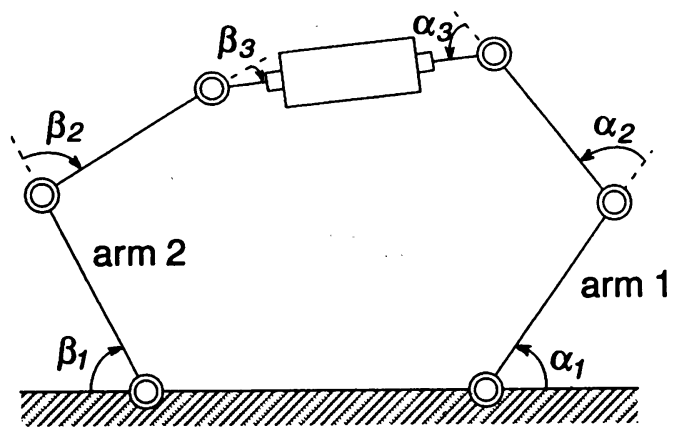

Fig. 4 Cooperative manipulation by two robot arms

ただし, $C_{\alpha \imath}=\cos \alpha_{\imath}, S_{\alpha \imath}=\sin \alpha_{\imath}, C_{\alpha \imath \jmath}=\cos \left(\alpha_{\imath}+\alpha_{\jmath}\right)$, $S_{\alpha \imath j}=\sin \left(\alpha_{i}+\alpha_{\jmath}\right)$ である.

(24) （26）式のうち切断関節の関節変数 $\beta_{3}$ が現れな い(25)，(26）式を用いて， $\beta_{1}$ と $\beta_{2}$ を $\alpha_{1}, \alpha_{2}$ ，およ び $\alpha_{3}$ から定めることができ，この 2 式から $W_{p}$ は以 下のように計算できる.

$$
\begin{gathered}
W_{p}=\left[\begin{array}{ll}
E & J_{p}^{T}
\end{array}\right]^{T} \\
J_{p}=-\left[\begin{array}{cc}
l_{1} S_{\beta_{1}}+l_{2} S_{\beta_{12}} & l_{2} S_{\beta_{12}} \\
-l_{1} C_{\beta_{1}}-l_{2} C_{\beta_{12}} & -l_{2} C_{\beta_{12}}
\end{array}\right]^{-1} \\
\times\left[\begin{array}{ccc}
l_{1} S_{\alpha 1}+l_{2} S_{\alpha 12}+l_{3} S_{\alpha 123} & l_{2} S_{\alpha 12}+l_{3} S_{\alpha 123} & l_{3} S_{\alpha 123} \\
l_{1} C_{\alpha 1}+l_{2} C_{\alpha 12}+l_{3} C_{\alpha 123} & l_{2} C_{\alpha 12}+l_{3} C_{\alpha 123} & l_{3} C_{\alpha 123}
\end{array}\right]
\end{gathered}
$$

(24), (25), (26) 式から $\boldsymbol{W}_{r}$ は以下のように計算でき る.

$$
\begin{gathered}
\boldsymbol{W}_{r}=\left[\begin{array}{ccc}
\boldsymbol{E} & \boldsymbol{J}_{r}{ }^{T}
\end{array}\right]^{T} \\
\boldsymbol{J}_{r}=-\left[\begin{array}{ccc}
1 & 1 & 1 \\
l_{1} S_{\beta_{1}}+l_{2} S_{\beta_{12}} & l_{2} S_{\beta_{12}} & 0 \\
-l_{1} C_{\beta_{1}}-l_{2} C_{\beta_{12}} & -l_{2} C_{\beta_{12}} & 0
\end{array}\right] \\
\times\left[\begin{array}{ccc}
1 & 1 & 1 \\
l_{1} S_{\alpha 1}+l_{2} S_{\alpha 12}+l_{3} S_{\alpha 123} & l_{2} S_{\alpha 12}+l_{3} S_{\alpha 123} & l_{3} S_{\alpha 123} \\
l_{1} C_{\alpha 1}+l_{2} C_{\alpha 12}+l_{3} C_{\alpha 123} & l_{2} C_{\alpha 12}+l_{3} C_{\alpha 123} & l_{3} C_{\alpha 123}
\end{array}\right]
\end{gathered}
$$

対象物の中心点の位置の軌道は $x, y, \theta$ の初期值を 0 $[\mathrm{m}], 0.3[\mathrm{~m}], 0$ 度, 終端值を $0.1[\mathrm{~m}], 0.35[\mathrm{~m}]$, -15 度として時間に関する 5 次の多項式で与え, 逆動 力学計算をおこなった. なお，駆動に関するて長性を各 関節のトルクのノルムが最小となるように利用した. こ のとき, アーム 2 の関節をすべて受動関節とみなした非 圥長駆動系と,もとのて長駆動系の関節トルクのノルム の比較を Fig. 6 に示す. この図から圥長駆動系が効率 よく出力を小さくする可能性をもつことがわかる. この 圥長駆動系は各関節すべてにアクチュエータを配置した 場合であるから同じ構造のらちでもっとも効率よく出力 を小さくした場合に相当する.

なお，（23）は片方のアームがすべて受動関節といら 特殊な場合に対応し，そのために圥長駆動系の場合との 差が大きく出た. しかしたとえば（23）の代わりに

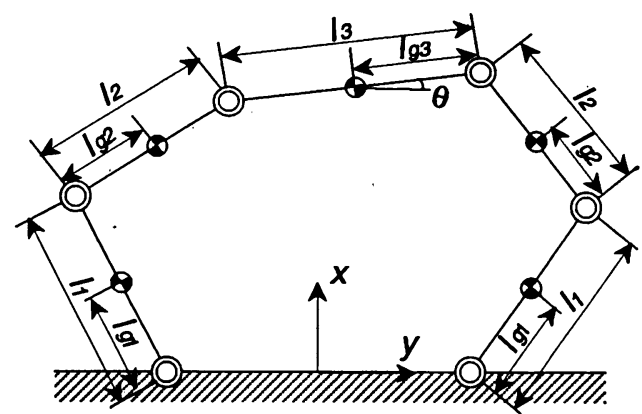

Fig. 5 Model of cooperative manipulation

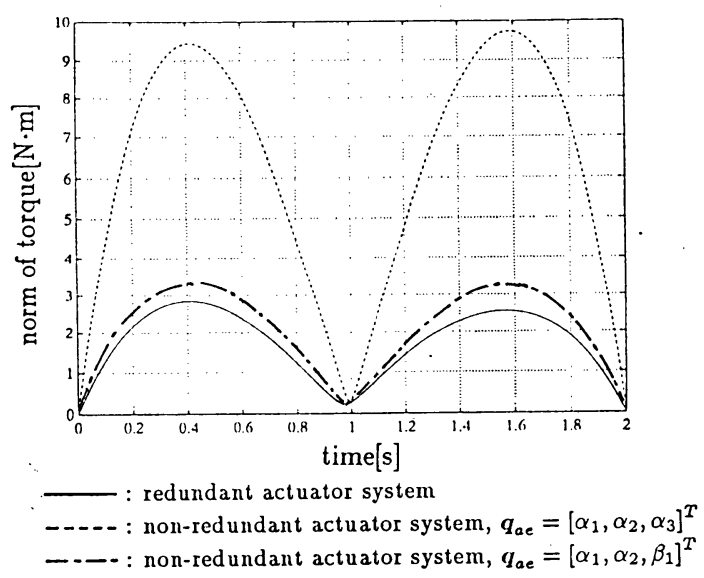

Fig. 6 Comparison of $\|\tau\|$

$$
q_{a e}=\left[\alpha_{1}, \alpha_{2}, \beta_{1}\right]^{T}
$$

ととれば，関節トルクのノルムは Fig. 6 の一点鎖線で与 えられ朵長駆動系の場合との差は小さく, 非圥長駆動系 でもアクチュエータの配置によって，出力を小さくする ことが可能となる. 厳密にはアクチュエータの質量を考 慮して動力学パラメータを変える必要があるが, 上の結 果はアクチュエータ取り付け時に参考になるものと思わ れる.

\section{5. お わりに}

本論文では, 駆動冗長性をもつ閉リンク機構に対して 従来提案されていた手法に比べて適用範囲の広い動力学 計算法を提案した. 本方法における冗長駆動系の逆動力 学計算には拘束の表現に能動関節に関する冗長な能動関 節のヤコビ行列を用いた. この表現は機構形状により, 直ちに計算できる、また，受動関節の存在などによらな い計算法である.

圥長駆動系は従来, 多指ハンドや複腕協調作業にみら れ, 圥長な力成分を内力として与えることで動力学計算 を执こなっていた1). しかし，破損の恐れのない物体を 扱うなどの理由で, 内力を陽に考慮する必要がない場合 
には, ラグランジュの未定定数の導入などの内力に対す る特別な配慮が不要であるため，本論文で提案した計算 アルゴリズムが簡潔であり，有用であるといえる．ただ し，内力を陽に考慮する必要がある場合については，従 来の方法と提案する方法をさらに詳しく検討する必要が あろら。

なお本論文は著者らの講演到をもとにまとめたもので あるが，本論文投稿と同時期に，著者らの手法と類似の 手法が中村 ${ }^{5}$ によって発表されたことを付記しておく. 文献 ${ }^{5)}$ に扣ける，閉リンク機構の運動を記述する一般化 座標の, 具体的で簡明な一つの選択法を与えているのが 本論文の手法であると位置づけることができよう，

\section{A. 付 録}

非圥長駆動系の閉リンク機構とそれに対応する冗長駆 動系の閉リンク機構のラグランジュ関数を $L_{a e}, L_{a r}$ と する.すなわち,

$$
\begin{gathered}
L_{a e}=L_{a e}\left(\boldsymbol{q}_{a e}, \dot{\boldsymbol{q}}_{a e}\right) \\
L_{a r}=L_{a r}\left(\boldsymbol{q}_{a e}, \boldsymbol{q}_{a r}, \dot{\boldsymbol{q}}_{a e}, \dot{\boldsymbol{q}}_{a r}\right)
\end{gathered}
$$

冗長駆動系のラグランジュ方程式は次式のよらになる.

$$
\frac{d}{d t}\left(\frac{\partial L_{a r}}{\partial \dot{\boldsymbol{q}}_{a}{ }^{T}}\right)-\frac{\partial L_{a r}}{\partial \boldsymbol{q}_{a}{ }^{T}}=\boldsymbol{\tau}_{a}^{T}
$$

ダランベールの原理より，仮想変位 $\delta \boldsymbol{q}_{a}=\boldsymbol{W}_{r} \delta \boldsymbol{q}_{a e}$ に対 して次式が成立する.

$$
\left\{\frac{d}{d t}\left(\frac{\partial L_{a r}}{\partial \dot{\boldsymbol{q}}_{a}^{T}}\right)-\frac{\partial L_{a r}}{\partial \boldsymbol{q}_{a}{ }^{T}}\right\} \boldsymbol{W}_{r} \delta \boldsymbol{q}_{a e}-\boldsymbol{\tau}_{a}{ }^{T} \boldsymbol{W}_{r} \delta \boldsymbol{q}_{a e}=0
$$

$\boldsymbol{q}_{a e}$ と $\dot{\boldsymbol{q}}_{a e}$ の独立性より $\frac{\partial \boldsymbol{q}_{a e}}{\partial \dot{\boldsymbol{q}}_{a e}{ }^{T}}=\mathbf{0}, \frac{\partial \dot{\boldsymbol{q}}_{a e}}{\partial \boldsymbol{q}_{a e}{ }^{T}}=\mathbf{0}$ および (10) 式より $\frac{\partial \boldsymbol{q}_{a r}}{\partial \dot{\boldsymbol{q}}_{a e^{T}}}=\mathbf{0}$ さらに $\frac{\partial \dot{\boldsymbol{q}}_{a r}}{\partial \dot{\boldsymbol{q}}_{a e^{T}}}=\frac{\partial \boldsymbol{q}_{a r}}{\partial \boldsymbol{q}_{a e^{T}}}$ の関係 を用いて

$$
\frac{d}{d t} \frac{\partial L_{a e}}{\partial \dot{\boldsymbol{q}}_{a e}{ }^{T}}=\frac{d}{d t}\left(\frac{\partial L_{a r}}{\partial \dot{\boldsymbol{q}}_{a e^{T}}{ }^{T}}\right)+\frac{d}{d t}\left(\frac{\partial L_{a r}}{\partial \dot{\boldsymbol{q}}_{a r} T} \frac{\partial \boldsymbol{q}_{a r}}{\partial \boldsymbol{q}_{a e^{T}}}\right)
$$

$$
\frac{\partial L_{a e}}{\partial \boldsymbol{q}_{a e^{T}}}=\frac{\partial L_{a r}}{\partial \boldsymbol{q}_{a e^{T}}}+\frac{\partial L_{a r}}{\partial \boldsymbol{q}_{a r}{ }^{T}} \frac{\partial \boldsymbol{q}_{a r}}{\partial \boldsymbol{q}_{a e^{T}}}+\frac{\partial L_{a e}}{\partial \dot{\boldsymbol{q}}_{a r}{ }^{T}} \frac{\partial \dot{\boldsymbol{q}}_{a r}}{\partial \boldsymbol{q}_{a e^{T}}}
$$

また $\frac{\partial L_{a e}}{\partial \dot{\boldsymbol{q}}_{a r}{ }^{T}} \frac{d}{d t}\left(\frac{\partial \boldsymbol{q}_{a r}}{\partial \boldsymbol{q}_{a e}{ }^{T}}\right)=\frac{\partial L_{a e}}{\partial \dot{\boldsymbol{q}}_{a r}{ }^{T}} \frac{\partial \dot{\boldsymbol{q}}_{a r}}{\partial \boldsymbol{q}_{a e}{ }^{T}}$ を考慮し, (33) 式に代入すると

$$
\left\{\frac{d}{d t}\left(\frac{\partial L_{a e}}{\partial \dot{\boldsymbol{q}}_{a e}{ }^{T}}\right)-\frac{\partial L_{a e}}{\partial \boldsymbol{q}_{a e}{ }^{T}}\right\} \delta \boldsymbol{q}_{a e}-\boldsymbol{\tau}_{a}^{T} \boldsymbol{W}_{r} \delta \boldsymbol{q}_{a e}=0
$$

となる.（36）式は任意の $\delta \boldsymbol{q}_{a e}$ に対して成立するから

$$
\frac{d}{d t}\left(\frac{\partial L_{a e}}{\partial \dot{\boldsymbol{q}}_{a e^{T}}}\right)-\frac{\partial L_{a e}}{\partial \boldsymbol{q}_{a e^{T}}}=\boldsymbol{\tau}_{a}^{T} \boldsymbol{W}_{r}
$$

一方, 非圥長駆動系のラグランジュ方程式は次式のよう 汇求められる.

$$
\frac{d}{d t}\left(\frac{\partial L_{a e}}{\partial \dot{\boldsymbol{q}}_{a e^{T}}}\right)-\frac{\partial L_{a e}}{\partial \boldsymbol{q}_{a e^{T}}}=\boldsymbol{\tau}_{a e^{T}}
$$

（37），(38）式を比較して，次式を得る.

$$
\begin{aligned}
& \boldsymbol{W}_{r}^{T} \boldsymbol{\tau}_{a}=\boldsymbol{\tau}_{a e} \\
& \text { 参 考 文 献 }
\end{aligned}
$$

1) J. Y.S. Luh and Y.F. Zheng: "Computation of Input Generalized Forces for Robots with Closed Kinematic Chain Mechanisms", IEEE Journal of Robotics and Automation, 2-7: pp. 95-103, 1985.

2) T. Ropponen and Y. Nakamura: "Singularity-Free Parameterization and Performance Analisis of Actuation Redundancy", Proc. of IEEEE International Conference on Robotics and Automation: pp. 806811, 1990.

3) Y. Nakamura and M. Ghodussi: "Dynamics Computation of Closed-Link Robot Mechanisms with Nonredundant and Redundant Actuators", IEEE Transactions on Robotics and Automation, 5-3 : pp. 294-302, 1989.

4）吉川，横小路, 渡辺. “駆動攵長性をもつ閉リンク機構 の動力学解析.”ロボティクス・メカトロニクス講演会 '92 講演論文集, pp. 105-108, 1992.

5) 中村. “パラレルメカニズムの動力学.”日本ロボット学 会誌, 10-6:pp.709-714, 1992.

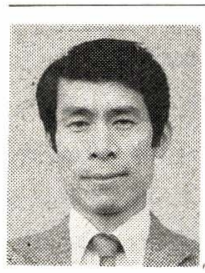

\section{吉川恒夫}

(Tsuneo YOSHIKAWA)

1941 年 12 月 19 日生. 1969 年京都大学 大学院博土課程修了. 同年, 同大学工学部 助手，1970年同助教授，1986年同教授（才 ートメーション研究施設, 1991 年より機 械工学教室）となり現在に至る。ロボット 工学, 制御工学の研究に従事. システム制御情報学会, 計測自 動制御学会, 日本機械学会, IEEE などの会員. 工学博士.

(日本ロボット学会正会員)

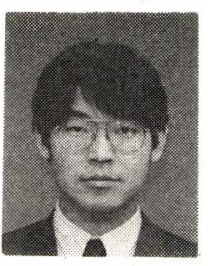

\section{横小路泰義}

(Yasuyoshi YOKOKOHJI)

1961 年 8 月 4 日生. 1988 年, 京都大学 大学院博士課程中途退学. 同大学工学部才 ートメーション研究施設助手, 応用システ 么科学教窒助手を経て, 1992 年 機械工学 教室助教授.ロポット工学の研究に従事. システム制御情報学会, 計測自動制御学会, 日本機械学会, IEEE などの会員. 工学博士. (日本ロボット学会正会員)

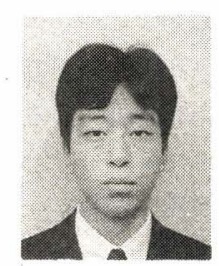

渡辺直満

(Naomitsu WATANABE) 1970 年 3 月 24 日生. 1992 年京都大学工 学部機械工学科卒業. 同年, 東京大学大学 院工学研究科修汒課程入学, 現在に至る. 閉リンク機構, マイクロマシンの研究に従 事. （日本ロボット学会学生会員） 